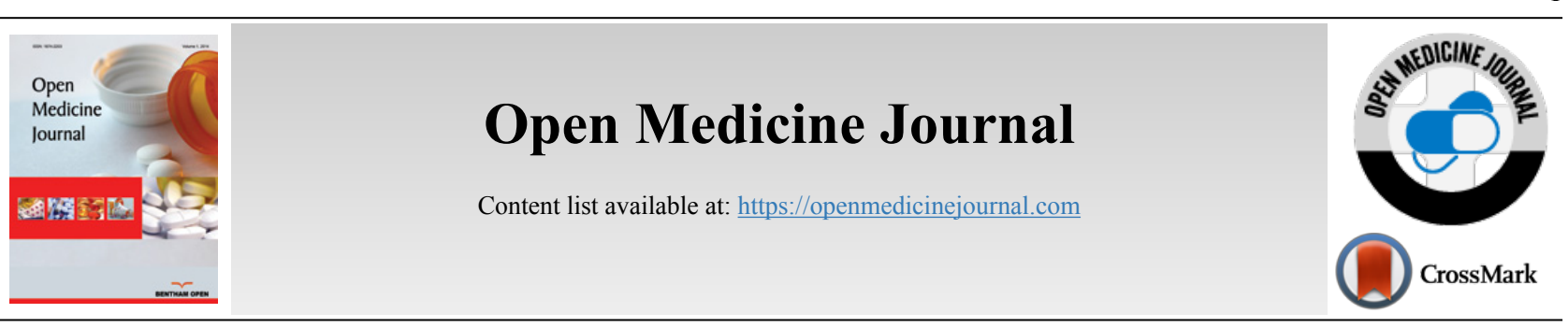

RESEARCH ARTICLE

\title{
Effects of Orally Administered Preliminary Analgesic Therapy in Diagnostic Colposcopy Patients: A Prospective Questionnaire Study
}

Georgios Michail ${ }^{1, *}$, Georgios Androutsopoulos ${ }^{1}$, Panagiotis Panas ${ }^{1}$, Georgios Valasoulis ${ }^{2}$, Ifigenia Papadimitriou ${ }^{1}$, Konstantinos Poulas ${ }^{3}$ and Georgios Adonakis ${ }^{1}$

${ }^{1}$ Department of Obstetrics \& Gynaecology, University Hospital of Patras, Rion, Greece

${ }^{2}$ Department of Obstetrics \& Gynaecology, University Hospital of Larisa, Larisa, Greece

${ }^{3}$ Department of Pharmacy, University of Patras, Rion, Greece

\section{Abstract: \\ Background:}

Colposcopy has a key role in the diagnostic work-up and management of abnormal cervical cytology, but it might generate negative feelings of mainly anxiety and pain to the patients undergoing such examination. These feelings are interrelated, with the anxiety fueling the painful sensations. The aim of our study was to investigate the effects of preliminary administration in terms of pain and anxiety relief that the preliminary administration of paracetamol would have on patients undergoing diagnostic colposcopy.

\section{Materials \& Methods:}

We conducted a single center prospective study which enrolled 112 patients with diagnosed or suspected cervical pathology who were examined at the Outpatient Colposcopy Clinic of Patras University Hospital, over a 7-months period. Patients were randomly assigned to one of the two groups. The interventional group received $1 \mathrm{gr}$ of paracetamol (acematiminofen) in pill form, 30 to 60 minutes before colposcopic assessment; the control group received no medication. At the end of consultation, all participants completed a 2-page questionnaire.

Results:

More patients of the interventional arm did not experience any pain at all during colposcopy compared with the control group. However, this difference was statistically not significant, probably because of the small number of patients. Moreover, there were no differences in mild and moderate pain rates between the interventional and control groups. Severe pain was only experienced by patients in the control group. Further data analysis from the first time as and for repeat colposcopy patients showed similar findings regarding pain intensity rates in the interventional and control group. When considering anxiety levels, no differences were observed between the two groups.

Conclusion:

The preliminary administration of low dose paracetamol in a pilot sample of colposcopy patients did not illustrate significant benefits in terms of experienced pain and anxiety levels.

Keywords: Paracetamol, Analgesic therapy, Diagnostic colposcopy, Pain, Cytology, Anxiety.

\begin{tabular}{l|l|l|r}
\hline Article History & Received: July 31, 2020 & Revised: November 25, 2020 & Accepted: November 26, 2020
\end{tabular}

\section{INTRODUCTION}

Cervical cancer represents a neoplasm usually affecting young individuals responsible for a high mortality burden worldwide, attributed to Human Papilloma Virus (HPV). Despite the successful ongoing anti-HPV vaccination programs, cervical precancer is unlikely to be eliminated in the near future. Cervical cancer screening programs are cytology

\footnotetext{
* Address correspondence to this author at Department of Obstetrics \& Gynaecology, University Hospital of Patras, Rion, Greece;

E-mail: gr.michail@yahoo.com
}

or HPV-biomarker-based, with colposcopy possessing a central role in the management of abnormal results. Although information elucidating aspects of the procedure is readily available, colposcopy remains a source of anxiety (re. causes of the abnormal smear, procedure itself, outcome, mid and longterm implications, etc.) and of interrelated pain for women [1], even in its purely diagnostic form, without involving cervical biopsies or treatments [2].

Several researchers have published their results on interventions targeting colposcopy-related anxiety, while 
insight has also been gained on aspects of colposcopy-caused pain $[3,4]$. Numerous nonpharmacologic methods (including music, videos, forced cough, visual distraction and gentle language) have been so far assessed [5]. However, data regarding prophylactic administration of pharmaceutical agents is more limited and conflicting [6].

Based on a University Hospital Outpatient Colposcopy Clinic covering extensive areas of Southwestern Greece, we conducted a single center prospective study with the primary aim of investigating the efficacy of preliminary administration of paracetamol to diagnostic colposcopy patients, in terms of pain and anxiety relief. The findings of this study have been presented in Poster form at the Eurogin 2020 Meeting held in Monaco, Monte Carlo.

\section{MATERIALS AND METHODS}

\subsection{Study Population}

The study was performed prospectively at the Outpatient Colposcopy Clinic of the University of Patras, during a 7months period. Our study population consisted of 112 patients with diagnosed or suspected cervical pathology (abnormal smear, persistent cervicitis, cervical bleeding, external condylomas, etc.), which were about to undergo diagnostic colposcopy either as a first exam or as a repeat procedure. Patients with hypersensitivity to paracetamol, severe liver or renal disease, renal calculi, psychiatric or antiepileptic medication, as well as pregnancy, were excluded from the study.

Patients were randomly assigned to one of the two groups, using a list of random numbers. The first group received $1 \mathrm{gr}$ paracetamol in pill form (interventional arm) 30 to 60 minutes before colposcopic assessment, while the other group received no medication (control group). Procedures lasted for 20 - 30 minutes and were strictly diagnostic; when biopsies were required, they were scheduled for a later appointment. One board-certified and experienced colposcopist performed all exams. Colposcopic findings, management options and future treatment plans were discussed in detail at the end of colposcopic assess- ment. Subsequently, all participating patients filled a 2-page questionnaire.

Consecutive colposcopy patients have been enrolled and no selection criteria applied during recruitment. The study has been approved by the University Hospital's Ethics Committee (HEC no.: 5922) before recruitment commenced and was conducted in accordance with the Helsinki Declaration and the principles of good clinical practice.

\subsection{Questionnaire}

A questionnaire for the collection of qualitative and quantitative data had been developed for the purposes of the study, representing a combined synthesis of STAI-AD (State Trait Anxiety Inventory for Adults, for assessing anxiety) and a numeric scale for the scoring of pain (0-10 Numeric Pain Rating Scale) [7, 8]. The sequence of "closed type" questions to assess anxiety and distress had predetermined answers (Not at all, barely, moderately, very much). The specific questions posed were 1. Did you feel calm? 2. Did you feel tension? 3. Did you feel secure? 4. Did you feel comfortable? 5. Did you feel upset? 6. Did you feel frightened? 7. Did you feel satisfied? 8. Did you feel worried? As for the rating of pain, patients were asked to point the number that represented more accurately the intensity of pain they experienced during the exam: "0" accounted for "no pain at all", and "10" accounted for the worst pain one could experience (Fig. 1).

The questionnaire was anonymized and it only required the age of the patient as inputs and whether this was the patient's first colposcopy. A copy of the questionnaire is attached as an appendix at the end of this article.

\subsection{Statistical Analysis}

In statistical analyses, continuous variables are presented as mean values with range, while categorical variables are presented as the number of cases (\%). Comparisons between groups were performed using one-way ANOVA (continuous variables) or Chi-square / Fisher's exact test (categorical variables). Statistical analyses were performed using IBM SPSS statistical package v.24 (IBM Corp. Armonk, NY). A p value $<0.05$ was considered statistically significant.

\section{RESULTS}

Overall, 112 women were enrolled in our study; the interventional group had 57 patients with an average age of 34.2 (range 19 to 65 ) years, while the control group had 55 patients with an average age of 34.6 (range 19 to 65 ) years.

When considering pain intensity in our study population, there were some differences between the two groups. In the interventional group, 16 patients $(28.07 \%)$ had no pain, while 41 patients $(71.93 \%)$ experienced mild or moderate pain. In the control group, only 12 patients $(21.82 \%)$ had no pain, while 41 patients $(74.54 \%)$ experienced mild or moderate pain and 2 patients $(3.6 \%)$ experienced severe pain.

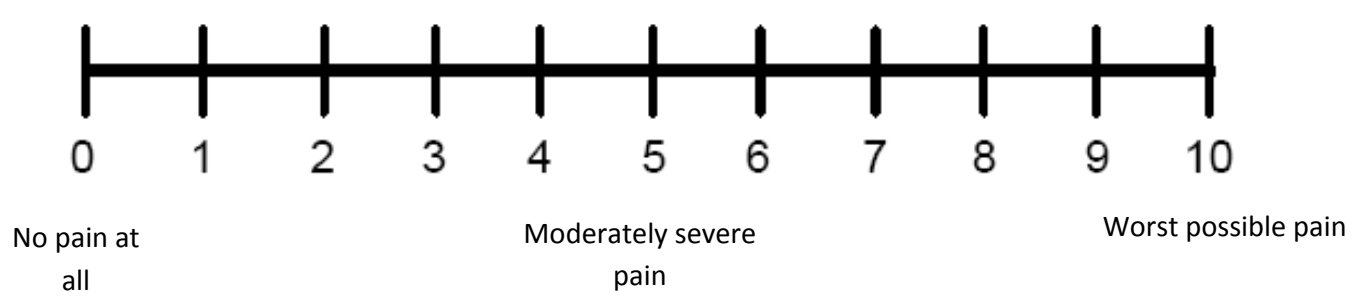

Fig. (1). The 0-10 Numeric Pain Rating Scale. 
Although more patients of the interventional group did not experience any pain during colposcopy compared with the control group, the difference was not statistically significant probably because of the small number of cases. Moreover, there were no differences in mild and moderate pain rates between the interventional and control group. Furthermore, severe pain was only experienced by patients of the control group. Details regarding pain intensity in both groups are presented in Table $\mathbf{1}$.

Further data analysis from patients undergoing colposcopy for the first time shows similar findings regarding pain intensity in both subgroups. In the interventional subgroup, 7 patients $(21.21 \%)$ had no pain, while 26 patients $(78.78 \%)$ experienced mild or moderate pain. In the control subgroup, only 3 patients $(13.63 \%)$ had no pain, while 18 patients $(81.81 \%)$ experienced mild or moderate pain and 1 patient (4.54\%) experienced severe pain. More patients in the interventional subgroup had no pain when compared with those of the control group, but that difference was not statistically significant. Additionally, there were no differences in mild and moderate pain rates in both subgroups. Apart from that, only 1 patient in the control subgroup experienced severe pain. Details regarding pain intensity in patients undergoing colposcopy for the first time are presented in Table 2 .

When analyzing data from patients undergoing repeat colposcopy, there were also similar findings regarding pain intensity in both subgroups. In the interventional subgroup, 9 patients $(37.5 \%)$ had no pain, while 15 patients (62.5\%) experienced mild or moderate pain. In the control subgroup, only 9 patients $(27.27 \%$ ) had no pain, while 23 patients $(69.69 \%)$ experienced mild or moderate pain and 1 patient $(3.03 \%)$ experienced severe pain. More patients in the interventional subgroup had no pain when compared with patients in control one, but that difference was not statistically significant. Furthermore, only 1 patient in the control subgroup experienced severe pain. Details regarding pain intensity in patients undergoing repeat colposcopy, are presented in Table 3.

When considering anxiety levels in our study population, there were no differences between the two groups. In the interventional group, 52 patients $(91.23 \%)$ had no or mild anxiety, while 5 patients $(8.77 \%)$ experienced moderate to severe anxiety. Likewise, in the control group, 49 patients $(89.09 \%)$ had no or mild anxiety, while 6 patients $(10.9 \%)$ experienced moderate to severe anxiety. Details regarding anxiety levels in both groups are presented in Table 4 .

Table 1. Number of patients in both groups and the corresponding apprehension of pain intensity they experienced during colposcopy.

\begin{tabular}{|c|c|c|c|c|c|c|}
\hline \multirow{2}{*}{$\begin{array}{c}\text { Pain Classification } \\
\text { No pain }\end{array}$} & \multirow{2}{*}{$\begin{array}{c}\text { Pain Intensity } \\
0\end{array}$} & \multicolumn{2}{|c|}{ Interventional Group (n: 57) } & \multicolumn{2}{|c|}{ Control Group (n: 55) } & \multirow{2}{*}{$\begin{array}{c}\text { p value } \\
0.5853\end{array}$} \\
\hline & & 16 & $16(28.07 \%)$ & 12 & $12(21.82 \%)$ & \\
\hline \multirow{3}{*}{ Mild } & 1 & 16 & \multirow{3}{*}{$32(56.14 \%)$} & 13 & \multirow{3}{*}{$35(63.63 \%)$} & \multirow{3}{*}{0.5378} \\
\hline & 2 & 6 & & 9 & & \\
\hline & 3 & 10 & & 13 & & \\
\hline \multirow{3}{*}{ Moderate } & 4 & 9 & \multirow{3}{*}{$9(15.79 \%)$} & 5 & \multirow{3}{*}{$6(10.9 \%)$} & \multirow{3}{*}{0.6308} \\
\hline & 5 & 0 & & 1 & & \\
\hline & 6 & 0 & & 0 & & \\
\hline \multirow{4}{*}{ Severe } & 7 & 0 & \multirow{4}{*}{$0(0 \%)$} & 0 & \multirow{4}{*}{$2(3.6 \%)$} & \multirow{4}{*}{0.4598} \\
\hline & 8 & 0 & & 1 & & \\
\hline & 9 & 0 & & 1 & & \\
\hline & 10 & 0 & & 0 & & \\
\hline
\end{tabular}

Table 2. Pain intensity among patients undergoing colposcopy for first time, in the interventional and the control group respectively.

\begin{tabular}{|c|c|c|c|c|c|c|}
\hline \multirow{2}{*}{$\begin{array}{c}\text { Pain Classification } \\
\text { No pain }\end{array}$} & \multirow{2}{*}{$\begin{array}{c}\text { Pain Intensity } \\
0\end{array}$} & \multicolumn{2}{|c|}{ Interventional Group (n: 33) } & \multicolumn{2}{|c|}{ Control Group (n: 22) } & \multirow{2}{*}{$\frac{p \text { value }}{0.7212}$} \\
\hline & & 7 & $7(21.21 \%)$ & 3 & $3(13.63 \%)$ & \\
\hline \multirow{3}{*}{ Mild } & 1 & 7 & \multirow{3}{*}{$19(57.57 \%)$} & 4 & \multirow{3}{*}{$14(63.63 \%)$} & \multirow{3}{*}{0.8662} \\
\hline & 2 & 5 & & 3 & & \\
\hline & 3 & 7 & & 7 & & \\
\hline \multirow{3}{*}{ Moderate } & 4 & 7 & \multirow{3}{*}{$7(21.21 \%)$} & 4 & \multirow{3}{*}{$4(18.18 \%)$} & \multirow{3}{*}{0.9451} \\
\hline & 5 & 0 & & 0 & & \\
\hline & 6 & 0 & & 0 & & \\
\hline \multirow{4}{*}{ Severe } & 7 & 0 & \multirow{4}{*}{$0(0 \%)$} & 0 & \multirow{4}{*}{$1(4.54 \%)$} & \multirow{4}{*}{0.8368} \\
\hline & 8 & 0 & & 1 & & \\
\hline & 9 & 0 & & 0 & & \\
\hline & 10 & 0 & & 0 & & \\
\hline
\end{tabular}


Table 3. Rating of pain among patients undergoing repeat colposcopy, in the interventional and the control group respectively.

\begin{tabular}{|c|c|c|c|c|c|c|}
\hline \multirow{2}{*}{$\begin{array}{c}\text { Pain Classification } \\
\text { No pain }\end{array}$} & \multirow{2}{*}{$\begin{array}{c}\text { Pain Intensity } \\
0 \\
\end{array}$} & \multicolumn{2}{|c|}{ Interventional Group (n: 24) } & \multicolumn{2}{|c|}{ Control Group (n: 33) } & \multirow{2}{*}{$\frac{\text { p value }}{0.5950}$} \\
\hline & & 9 & $9(37.5 \%)$ & 9 & $9(27.27 \%)$ & \\
\hline \multirow{3}{*}{ Mild } & 1 & 9 & \multirow{3}{*}{$13(54.16 \%)$} & 9 & \multirow{3}{*}{$21(63.63 \%)$} & \multirow{3}{*}{0.6555} \\
\hline & 2 & 1 & & 6 & & \\
\hline & 3 & 3 & & 6 & & \\
\hline \multirow{3}{*}{ Moderate } & 4 & 2 & \multirow{3}{*}{$2(8.33 \%)$} & 1 & \multirow{3}{*}{$2(6.06 \%)$} & \multirow{3}{*}{0.8466} \\
\hline & 5 & 0 & & 1 & & \\
\hline & 6 & 0 & & 0 & & \\
\hline \multirow{4}{*}{ Severe } & 7 & 0 & \multirow{4}{*}{$0(0 \%)$} & 0 & \multirow{4}{*}{$1(3.03 \%)$} & \multirow{4}{*}{0.8718} \\
\hline & 8 & 0 & & 0 & & \\
\hline & 9 & 0 & & 1 & & \\
\hline & 10 & 0 & & 0 & & \\
\hline
\end{tabular}

Table 4. Intensity of anxiety levels in the interventional and the control group respectively. (For both groups, first and repeat colposcopy procedures are taken together)

\begin{tabular}{|c|c|c|c|}
\hline Anxiety Classification & Interventional Group (n: 57) & Control Group (n: 55) & p value \\
\hline Nill to mild & $52(91.23 \%)$ & $49(89.09 \%)$ & 0.9503 \\
\hline Moderate to severe & $5(8.77 \%)$ & $6(10.9 \%)$ & 0.9503 \\
\hline
\end{tabular}

\section{DISCUSSION}

\subsection{Colposcopy and Negative Feelings}

Colposcopy - related anxiety and pain represent well documented procedural issues inasmuch that the US preventive Task Force currently regards them as harms related with cervical cancer screening [9]. The physical and psychological consequences of colposcopy are interrelated, with an anticipated and justified procedural psychosomatic burden based on the remote position of the cervix, which inevitably entails a copious exam in close proximity with the physician.

The study of Bosgraaf et al. illustrated that psychological stress before colposcopy was seen as being caused both by an unsatisfactory explanation of abnormal cervical smears and the colposcopy procedure itself [10]. The authors underscored that a fear of cancer, pain and discomfort, embarrassment, waiting time in the hospital and a longer interval between referral and the actual colposcopy appointment increased psychological stress and anxiety. Anxious or depressive patients can be more nervous regarding the colposcopic procedure [11].

Even though the pain associated with colposcopy is generally minimal, this particular feeling is multifactorial and anxiety itself can precipitate the increased perception of pain and decreased pain tolerance $[12,13]$. The intensity of pain is increased in interventional colposcopic procedures (biopsies, treatments) $[14,15]$. Pain scores can drop significantly when colposcopy is performed by more experienced physicians [16].

Taken together, pain expectancy and anxiety fuel discomfort diminish the acceptability of colposcopic examinations, posing difficulties in accomplishing the colposcopy procedure [17]. Additionally, this procedure-related stress might prove detrimental for compliance rates, influencing adherence negatively and increasing the risk of non-attendance in the subsequent follow-up colposcopy visits $[5,17,18]$.

\subsection{Possible Interventions}

Despite the abundance of articles, the literature predominantly focuses on interventional colposcopy (i.e. involving biopsies or treatments); fewer published studies have assessed purely diagnostic colposcopy.

Several approaches have been so far proposed for colposcopy-related anxiety, such as allowing the patient to follow the ongoing procedure via video-colposcopy [12], relaxing music or videos with stress-relieving themes that help to distract the patients' attention $[19,20]$. Furthermore, some authors acknowledge that the provision of both sensory (i.e., how the procedure will feel) and procedural information (i.e., what exactly the procedure will involve), results in reduced anxiety, pain, and distress [21]. In this setting, leaflets and information videos have been proposed as a means to alleviate anxiety with mixed results $[3,22,23]$. The Cochrane metaanalysis [24] on colposcopy-related anxiety concludes that video colposcopy and playing music represent the most effective interventions. As for informative leaflets, the metaanalysis considers them unhelpful in diminishing anxiety, merely regarding them useful in providing procedural informed consent.

Providing women with details of the likely sensations during colposcopy counseling as well as explaining what to expect in terms of procedural steps and time may ensure expectations are appropriate and may also reduce the pain experienced during colposcopy $[5,25]$. Since procedure-related pain and discomfort are closely associated, decreasing pain with medical or alternative methods would also alleviate sensations of discomfort, and ultimately prevent an unpleasant colposcopy experience [26]. Chan et al. documented beneficial effects of music in terms of significantly lower pain and less anxiety [4]. The prospective study of Carwile et al. used 
passive visual distraction and concluded that this approach reduced perceived pain but not overall anxiety [27].

Previous studies evaluating pain relief effectiveness of oral ibuprofen during interventional colposcopy [6] concluded that this agent provided no advantage over placebo in decreasing colposcopy pain. In their comprehensive review, Ireland et al. [25] advocate that current evidence does not support the routine use of any systemic or local anesthesia during colposcopy. In particular, oral analgesia, such as NSAIDs, topical lidocaine-prilocaine cream, or lignocaine or benzocaine sprays were found to be ineffective strategies for pain control during colposcopy [25]. Finally, the most recent Cochrane meta-analysis on colposcopy-related pain relief, focused on interventional colposcopy and illustrated limited value of oral analgesics [14].

\subsection{Paracetamol and Colposcopy}

Older uncontrolled studies suggested that oral nonsteroidal anti-inflammatory drugs (NSAIDs) are beneficial for colposcopy [28]. Similar to NSAIDs, paracetamol also inhibits the enzyme cyclooxygenase, however, its action is in the central nervous system rather than the periphery [29, 25]. Despite its inferiority compared to ibuprofen for control of uterine pain, paracetamol represents a valid option for women who cannot tolerate NSAIDs [25, 29].

\subsection{Our Study Results}

In this study, patients were prospectively recruited and all procedures have been performed by one single board-certified colposcopist. The choice of the particular pharmaceutical agent (paracetamol) was primarily based on its pharmaceutical properties (weak inhibitor of prostaglandin biosynthesis in the $\mathrm{CNS}$, featuring analgesic and anti-febrile properties), its wide availability and popularity, the absence of severe untoward or side effects and low price. The design of our study mandated that pharmaceutical administrations were kept in a minimal interventional frame, avoiding drugs with anxiolytic properties. It is plausible that if other medications had been administered, then these interventions might have altered the content of answers in the questionnaires.

As was also observed by Valdini et al., the documented average scores of distress for patients experiencing their first colposcopy were higher in all aspects than those in women having repeat examinations [11].

\subsection{Possible Limitations in Our Study}

Potential limitations of the study might represent: i) the non-homogenous sample (first/repeat procedure); however, the groups were similar in this respect; ii) vaccination status was not documented; we have anecdotally observed less difficulties and improved co-operation with the procedure among vaccinated individuals and iii) paracetamol was administered in standard dose; it is possible that an increased dosage of paracetamol $1500 \mathrm{mg}$ of this medication might have a more pronounced effect and therefore yield statistically significant results [30].

\section{CONCLUSION}

Preliminary medication could have a beneficial role in anxiety and pain control for patients undergoing diagnostic colposcopy. Future studies assessing candidate pharmaceutical agents need to accommodate several confounding factors; whereas the level of knowledge the patient has regarding the colposcopy procedure itself might influence the results unpredictably.

\section{ETHICS APPROVAL AND CONSENT TO PARTI- CIPATE}

The study has been approved by the University Hospital of Patras, Greece Ethics Committee (HEC no.: 5922) before recruitment commenced.

\section{HUMAN AND ANIMAL RIGHTS}

No animals were used in this research. All human research procedures were followed in accordance with the ethical standards of the committee responsible for human experimentation (institutional and national), and with the Helsinki Declaration of 1975, as revised in 2013.

\section{CONSENT FOR PUBLICATION}

Written informed consent was obtained from each participant prior to the study.

\section{AVAILABILITY OF DATA AND MATERIALS}

Not applicable.

FUNDING

None.

\section{CONFLICT OF INTEREST}

The authors declare no conflict of interest, financial or otherwise.

\section{ACKNOWLEDGEMENTS}

The authors would like to thank Ms Afroditi Moumouri for processing a part of this study's data and Ms Andriana Kokkovika for her valuable contribution in the accomplishment of the study.

\section{APPENDIX \\ QUESTIONNAIRE}
1. Did you feel calm?
$\square$ Not at all
$\square$ Barely
$\square$ Moderately
$\square$ Very much
2. Did you feel in tension?
$\square$ Not at all
$\square$ Barely 
$\square$ Moderately

$\square$ Very much

3. Did you feel secure?

$\square$ Not at all

$\square$ Barely

$\square$ Moderately

$\square$ Very much

4. Did you feel comfortable?

$\square$ Not at all

$\square$ Barely

$\square$ Moderately

$\square$ Very much

5. Did you feel upset?

$\square$ Not at all

$\square$ Barely

$\square$ Moderately

$\square$ Very much

6. Did you feel frightened?

$\square$ Not at all

$\square$ Barely

$\square$ Moderately

$\square$ Very much

7. Did you feel satisfied?

$\square$ Not at all

$\square$ Barely

$\square$ Moderately

$\square$ Very much

8. Did you feel worried?

$\square$ Not at all

$\square$ Barely

$\square$ Moderately

$\square$ Very much

\section{REFERENCES}

[1] Handelzalts JE, Krissi H, Levy S, Broitman M, Binyamin L, Peled Y. Multidimensional associations of pain and anxiety before and after colposcopy. Int J Gynaecol Obstet 2015; 131(3): 297-300. [http://dx.doi.org/10.1016/j.ijgo.2015.05.038]

[2] Kongsawatvorakul C, Charakorn C, Paiwattananupant K, Lekskul N, Rattanasiri S, Lertkhachonsuk AA. Limited impact of music therapy on patient anxiety with the large loop excision of transformation zone procedure - a randomized controlled trial. Asian Pac J Cancer Prev 2016; 17(6): 2853-6. [PMID: 27356701]

[3] Freeman-Wang T, Walker P, Linehan J, Coffey C, Glasser B, Sherr L. Anxiety levels in women attending colposcopy clinics for treatment for cervical intraepithelial neoplasia: A randomised trial of written and video information. BJOG 2001; 108(5): 482-4. [http://dx.doi.org/10.1111/j.1471-0528.2001.00121.x]
[4] Chan YM, Lee PW, Ng TY, Ngan HY, Wong LC. The use of music to reduce anxiety for patients undergoing colposcopy: A randomized trial. Gynecol Oncol 2003; 91(1): 213-7.

[http://dx.doi.org/10.1016/S0090-8258(03)00412-8]

[5] Kola-Palmer S, Walsh JC, Rogers M. Patients' perceptions of colposcopy pain. Eur J Cancer Care (Engl) 2016; 25(1): 49-56. [http://dx.doi.org/10.1111/ecc.12343]

[6] Church L, Oliver L, Dobie S, Madigan D, Ellsworth A. Analgesia for colposcopy: Double-masked, randomized comparison of ibuprofen and benzocaine gel. Obstet Gynecol 2001; 97(1): 5-10. [http://dx.doi.org/10.1097/00006250-200101000-00002]

[7] Marteau TM, Bekker H. The development of a six-item short-form of the state scale of the Spielberger State-Trait Anxiety Inventory (STAI). Br J Clin Psychol 1992; 31(3): 301-6.

[http://dx.doi.org/10.1111/j.2044-8260.1992.tb00997.x]

[8] McCaffery M, Pasero C. Pain: clinical manual: Mosby CV. 1999.

[9] Curry SJ, Krist AH, Owens DK, et al. Screening for cervical cancer: US preventive services task force recommendation statement. JAMA 2018; 320(7): 674-86.

[http://dx.doi.org/10.1001/jama.2018.10897] [PMID: 30140884]

[10] Bosgraaf RP, de Jager WC, Servaes P, Prins JB, Massuger LF, Bekkers RL. Qualitative insights into the psychological stress before and during colposcopy: A focus group study. J Psychosom Obstet Gynaecol 2013; 34(4): 150-6.

[http://dx.doi.org/10.3109/0167482X.2013.849688]

[PMID: 24188786]

[11] Valdini A, Esielionis P. Measurement of colposcopy-associated distress using the psychosocial effects of having an abnormal pap smear-questionnaire in a Latina population. J Low Genit Tract Dis 2004; 8(1): 25-32.

[http://dx.doi.org/10.1097/00128360-200401000-00007] [PMID: 15874833]

[12] Walsh JC, Curtis R, Mylotte M. Anxiety levels in women attending a colposcopy clinic: A randomised trial of an educational intervention using video colposcopy. Patient Educ Couns 2004; 55(2): 247-51. [http://dx.doi.org/10.1016/j.pec.2003.09.012] [PMID: 15530762]

[13] Kola S, Walsh JC, Hughes BM, Howard S. Attention focus, trait anxiety and pain perception in patients undergoing colposcopy. Eur $\mathrm{J}$ Pain 2012; 16(6): 890-900.

[http://dx.doi.org/10.1002/j.1532-2149.2011.00068.x] [PMID: 22337343]

[14] Gajjar K, Martin-Hirsch PP, Bryant A, Owens GL. Pain relief for women with cervical intraepithelial neoplasia undergoing colposcopy treatment. Cochrane Database Syst Rev 2016; 7CD006120 [http://dx.doi.org/10.1002/14651858.CD006120.pub4] [PMID: 27428114]

[15] Kola S, Walsh JC. Patients' psychological reactions to colposcopy and LLETZ treatment for cervical intraepithelial neoplasia. Eur J Obstet Gynecol Reprod Biol 2009; 146(1): 96-9.

[http://dx.doi.org/10.1016/j.ejogrb.2009.05.005] [PMID: 19487067]

[16] Abdelhakim AM, Samy A, Abbas AM. Effect of music in reducing patient anxiety during colposcopy: A systematic review and metaanalysis of randomized controlled trials. J Gynecol Obstet Hum Reprod 2019; 48(10): 855-61.

[http://dx.doi.org/10.1016/j.jogoh.2019.07.007] [PMID: 31276848]

[17] Bogani G, Serati M, Cromi A, et al. Local anesthetic versus forced coughing at colposcopic-guided biopsy: A prospective study. Eur J Obstet Gynecol Reprod Biol 2014; 181: 15-9.

[http://dx.doi.org/10.1016/j.ejogrb.2014.07.022] [PMID: 25124705]

[18] Kola-Palmer S, Walsh JC. Correlates of psychological distress immediately following colposcopy. Psychooncology 2015; 24(7): 819-24.

[http://dx.doi.org/10.1002/pon.3738] [PMID: 25581290]

[19] Rickert VI, Kozlowski KJ, Warren AM, Hendon A, Davis P. Adolescents and colposcopy: The use of different procedures to reduce anxiety. Am J Obstet Gynecol 1994; 170(2): 504-8.

[http://dx.doi.org/10.1016/S0002-9378(94)70218-7] [PMID: 8116704]

[20] Danhauer SC, Marler B, Rutherford CA, et al. Music or guided imagery for women undergoing colposcopy: A randomized controlled study of effects on anxiety, perceived pain, and patient satisfaction. $\mathrm{J}$ Low Genit Tract Dis 2007; 11(1): 39-45.

[http://dx.doi.org/10.1097/01.lgt.0000230206.50495.4c] [PMID: 17194950]

[21] O'Connor M, Waller J, Gallagher P, et al. Understanding Women's Differing Experiences of Distress after Colposcopy: A Qualitative Interview Study. Women's health issues : Official publication of the Jacobs Institute of Women's Health 2015; 25(5): 528-34. 
[http://dx.doi.org/10.1016/j.whi.2015.05.009]

[22] Howells RE, Dunn PD, Isasi T, et al. Is the provision of information leaflets before colposcopy beneficial? A prospective randomised study. Br J Obstet Gynaecol 1999; 106(6): 528-34. [http://dx.doi.org/10.1111/j.1471-0528.1999.tb08319.x]

[PMID: 10426608]

[23] Tahseen S, Reid PC. Psychological distress associated with colposcopy: Patients' perception. Eur J Obstet Gynecol Reprod Biol 2008; 139(1): 90-4.

[http://dx.doi.org/10.1016/j.ejogrb.2007.09.001] [PMID: 17980478]

[24] Galaal K, Bryant A, Deane KH, Al-Khaduri M, Lopes AD. Interventions for reducing anxiety in women undergoing colposcopy. Cochrane Database Syst Rev 2011; (12): CD006013

[http://dx.doi.org/10.1002/14651858.CD006013.pub3]

[PMID: 22161395]

[25] Ireland LD, Allen RH. Pain management for gynecologic procedures in the office. Obstet Gynecol Surv 2016; 71(2): 89-98.

[http://dx.doi.org/10.1097/OGX.0000000000000272]

[PMID: 26894801]

[26] Baser E, Togrul C, Ozgu E, Esercan A, Caglar M, Gungor T. Effect of pre-procedural state-trait anxiety on pain perception and discomfort in women undergoing colposcopy for cervical cytological abnormalities. Asian Pac J Cancer Prev 2013; 14(7): 4053-6.

[http://dx.doi.org/10.7314/APJCP.2013.14.7.4053] [PMID: 23991951]

[27] Carwile JL, Feldman S, Johnson NR. Use of a simple visual distraction to reduce pain and anxiety in patients undergoing colposcopy. J Low Genit Tract Dis 2014; 18(4): 317-21.

[http://dx.doi.org/10.1097/LGT.0000000000000024]

[PMID: 24977629

[28] Rodney WM, Huff M, Euans D, Hutchins C, Clement K, McCall JW III. Colposcopy in family practice: pilot studies of pain prophylaxis and patient volume. Fam Pract Res J 1992; 12(1): 91-8. [PMID: 1312759]

[29] Allen RH, Micks E, Edelman A. Pain relief for obstetric and gynecologic ambulatory procedures. Obstet Gynecol Clin North Am 2013; 40(4): 625-45.

[http://dx.doi.org/10.1016/j.ogc.2013.08.005] [PMID: 24286993]

[30] Bannwarth B, Pehourcq F. Pharmacological rationale for the clinical use of paracetamol. Drugs 2003; 63(Special Issue 2): 5-13.

[http://dx.doi.org/10.2165/00003495-200363992-00003]

(C) 2021 Michail et al.

This is an open access article distributed under the terms of the Creative Commons Attribution 4.0 International Public License (CC-BY 4.0), a copy of which is available at: https://creativecommons.org/licenses/by/4.0/legalcode. This license permits unrestricted use, distribution, and reproduction in any medium, provided the original author and source are credited. 